\title{
Plasma exchange and hemodialysis for severe manifestations of multiple wasp stings in a child
}

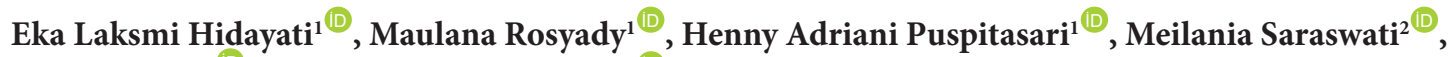 \\ Angela Grace $^{1}{ }^{\mathbb{D}}$, Cahyani Gita Ambarsari ${ }^{1 * \mathbb{D}}$ \\ ${ }^{1}$ Department of Child Health, Faculty of Medicine Universitas Indonesia - Cipto Mangunkusumo Hospital, Jakarta, Indonesia \\ ${ }^{2}$ Department of Pathology Anatomy, Faculty of Medicine Universitas Indonesia - Cipto Mangunkusumo Hospital, Jakarta, Indonesia
}

\section{AR T I C L E I N F O}

Article Type:

Case Report

\section{Article History:}

Received: 7 February 2020

Accepted: 1 May 2020

Published online: 14 May 2020

\section{Keywords:}

Sting, Hemolysis, Multiple organ failure, Rhabdomyolysis, Plasma exchange, Wasp

\begin{abstract}
A B S T R A C T
Wasp stings occur frequently in developing countries and often lead to fatal outcomes due to the effects of wasp venom. Hemolysis and rhabdomyolysis often complicate wasp stings and result in acute kidney injury (AKI). We report a case of multiple wasp stings leading to AKI and multiple organ dysfunction syndrome (MODS) in a 9-year-old Indonesian girl. Kidney biopsy revealed acute tubular necrosis and acute interstitial nephritis. Despite delayed admission, she recovered in 33 days after 3 days of intravenous steroid administration, eight sessions of intermittent hemodialysis, and two sessions of plasma exchange (PE). Complete recovery of kidney function, indicated by normal diuresis, normal estimated glomerular filtration rate, and negative albuminuria, was reached within 12 weeks. This case showed that immediate admission following multiple wasp stings (particularly $>10$ stings) to initiate early dialysis is important to promptly remove toxins and preserve kidney function. The case also showed that PE can be beneficial in cases of hemolysis and rhabdomyolysis complicated by MODS.
\end{abstract}

Implication for health policy/practice/research/medical education:

All patients with multiple wasp stings should undergo complete laboratory examination. If specific organ involvements are identified, referral to centers with extracorporeal treatment modalities could be required.

Please cite this paper as: Hidayati EL, Rosyady M, Puspitasari HA, Saraswati M, Grace A, Ambarsari CG. Plasma exchange and hemodialysis for severe manifestations of multiple wasp stings in a child. J Renal Inj Prev. 2020; 9(3): e27. doi: 10.34172/jrip.2020. e27.

\section{Introduction}

The incidence of wasp sting globally is approximately $56 \%$ to $94 \%$. Wasp stings can result in various manifestations, from local reactions to life-threatening conditions (1). The age of the victim, location and number of stings, comorbidities, and history of allergy affect the severity of systemic reactions (2). From 2016 until the end of 2019, as many as 667 wasp attacks in remote areas of Indonesia-a tropical country-were reported in the news, resulting in 10 fatalities (3). Despite the number of cases, only one medical case report of wasp sting has been published from Indonesia. More such reports could provide clearer understanding about managing such cases (4).

Wasp toxin can produce acute kidney injury (AKI), pancreatitis, hepatitis, myocarditis, coagulation disorder, respiratory distress, rhabdomyolysis, intravascular hemolysis, and anaphylactic shock $(5,6)$. The likelihood of multi-organ failure increases the urgency of performing laboratory workup of various parameters following wasp sting. Hemolysis and rhabdomyolysis are the most frequent complications of wasp sting and contribute to the incidence of AKI, which can result in fatal outcomes (7).

We present a case of multiple wasp stings leading to AKI and multiple organ dysfunction syndrome (MODS) in a 9-year-old girl from Indonesia, who was admitted to the hospital 3 days after being stung. Despite the delayed admission, she managed to recover in 33 days following intravenous (IV) steroid administration, intermittent hemodialysis (IHD), and plasma exchange (PE).

\section{Case Presentation}

A 9-year-old Indonesian girl was admitted to the 
emergency room of the national referral hospital in Jakarta due to generalized swelling from 3 days before admission after she had been stung by a large number of wasps. She was walking in an unattended yard with a friend without noticing that a group of kids was disturbing a wasp nest on a tree. When the wasps burst out of the nest, she ran home to get help from her father, but she could not escape the wasps and was stung multiple times.

She was first treated at home by his uncle, who was a paramedic. However, her extremities were swollen, and IV access could not be established. She only received paracetamol $500 \mathrm{mg}$ per oral (PO) every 8 hours. One day before admission to the emergency room, she had nausea and vomiting, and the swelling extended to the periorbital region and all extremities. She was jaundiced and produced a small amount of dark-brown urine.

Upon admission, there were 93 lesions of wasp stings noted (Figure 1A-C), together with generalized swelling, prominent jaundice, and anuria. She had a low-grade fever $\left(37.8^{\circ} \mathrm{C}\right)$ and normal blood pressure $(110 / 60 \mathrm{~mm}$ $\mathrm{Hg})$. Laboratory results on admission are summarized in Table 1. She was administered IV fluid, IV bicarbonate, IV calcium gluconate, IV furosemide, and salbutamol respule by nebulization. Despite treatment, the anuria did not improve.

Hemodialysis (HD) was immediately started, in addition to transfusion of packed red cells. She received high-dose IV methylprednisolone for 3 days, continued with methylprednisolone PO $40 \mathrm{mg}$ daily, which was then tapered off for 8 weeks. PE was initiated after the second HD session. Urinary output was first noted on day 7 following wasp stings, improved gradually, and returned to normal on day 23 (Figure 2A). Hemolysis, reflected by the fluctuating levels of hemoglobin despite transfusions of packed red cells, was noted (Figure 2B).

Kidney biopsy was performed on day 23 and revealed acute tubular necrosis and acute interstitial nephritis (Figure 3A-C). After eight HD sessions, three transfusions of packed red cells, and two PE sessions, her kidney function normalized. A follow-up clinic visit 12 weeks following the wasp stings showed negative results for albuminuria and a normal urinary albumin-to-creatinine ratio $(29 \mathrm{mg} / \mathrm{g})$.

\section{Discussion}

Wasp stings are frequently reported in developing countries and often lead to fatal outcomes (7). A study of 1091 cases of wasp stings in China reported a mortality rate of $5.1 \%$, and a majority of patients had MODS, non-anaphylactic reaction, and other complications due to toxic effects of wasp venom (7). The outcome of the hypersensitivity reaction to wasp venom is usually more favorable than the outcome of the non-anaphylactic reaction (7). Our patient had a non-anaphylactic reaction, which was indicated by the normal IgE level.
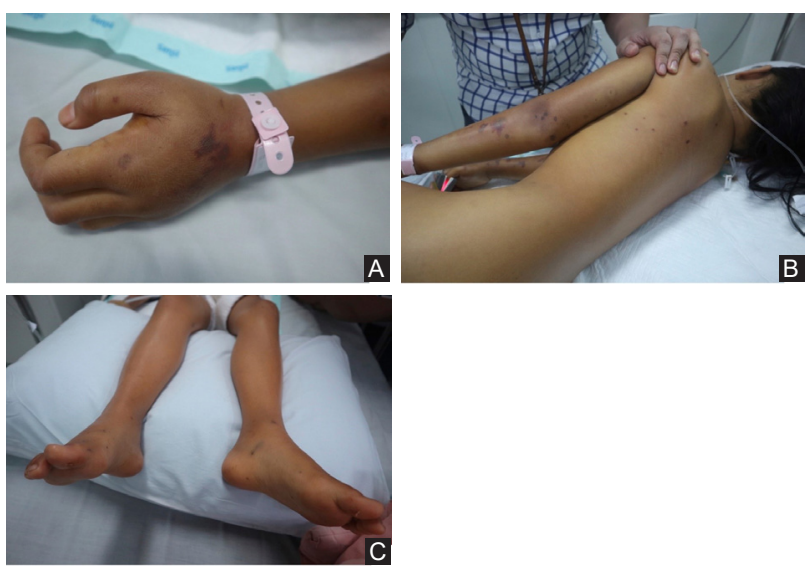

Figure 1. (A) Stings on the dorsal part of the right hand. (B) Multiple stings are seen on the back, trunk, and right forearm. (C) Stings on the legs.

Table 1. Laboratory results on admission

\begin{tabular}{|c|c|c|}
\hline Parameters & References & Day of admission \\
\hline \multicolumn{3}{|c|}{ Blood test } \\
\hline Hemoglobin (g/dL) & 11.5 & 9.3 \\
\hline Leucocyte $(1000 / \mu \mathrm{L})$ & $4-12$ & 48.23 \\
\hline Platelet $(1000 / \mu \mathrm{L})$ & $150-400$ & 90 \\
\hline Total Bilirubin (mg/dL) & $0-0.99$ & 29.68 \\
\hline Direct Bilirubin (mg/dL) & $0-0.29$ & 23.38 \\
\hline Indirect Bilirubin (mg/dL) & $0.1-0.7$ & 6.3 \\
\hline Lactate dehydrogenase (U/L) & $0-214$ & 16440 \\
\hline Creatine kinase (U/L) & $0-153$ & 115716 \\
\hline Blood smear morphology & & $\begin{array}{l}\text { Normocytic } \\
\text { normochromic, } \\
\text { anisocytosis, burr } \\
\text { cell, polychromasia }\end{array}$ \\
\hline Ureum (mg/dL) & $0-49$ & 216.6 \\
\hline Creatinine (mg/dL) & $0.6-1.2$ & 4.9 \\
\hline $\begin{array}{l}\text { eGFR new Schwartz }(\mathrm{mL} / \\
\left.\min / 1.73 \mathrm{~m}^{2}\right)\end{array}$ & $94-142$ & 10.5 \\
\hline Potassium (mEq/L) & $3.3-5.4$ & 6.8 \\
\hline Calcium (mmol/L) & $1.01-1.31$ & 0.73 \\
\hline $\mathrm{HCO} 3$ (mmol/L) & $21-25$ & 10.5 \\
\hline AST (U/L) & $0-50$ & 7015.5 \\
\hline $\operatorname{ALT}(U / L)$ & $0-38$ & 2294.8 \\
\hline Amilase (U/L) & $<39$ & 113 \\
\hline Lipase (U/L) & $<37$ & 313 \\
\hline $\operatorname{lgE}(\mathrm{IU} / \mathrm{mL})$ & $<200$ & 86.5 \\
\hline
\end{tabular}

Urine test (Day 7 post wasp stings)

\begin{tabular}{lll}
\hline Myoglobin Urine & Negative & Negative \\
Urine analysis & & \\
Albumin & Negative & $3+$ \\
Blood & Negative & $3+$ \\
Bilirubin & Negative & $1+$ \\
Erythrocyte & $1-3 / \mathrm{HPF}$ & $2-4 / \mathrm{HPF}$ \\
\hline
\end{tabular}

eGFR, estimated glomerular filtration rate; ALT, alanine aminotransferase; AST, aspartate aminotransferase; HPF, high-power field. 

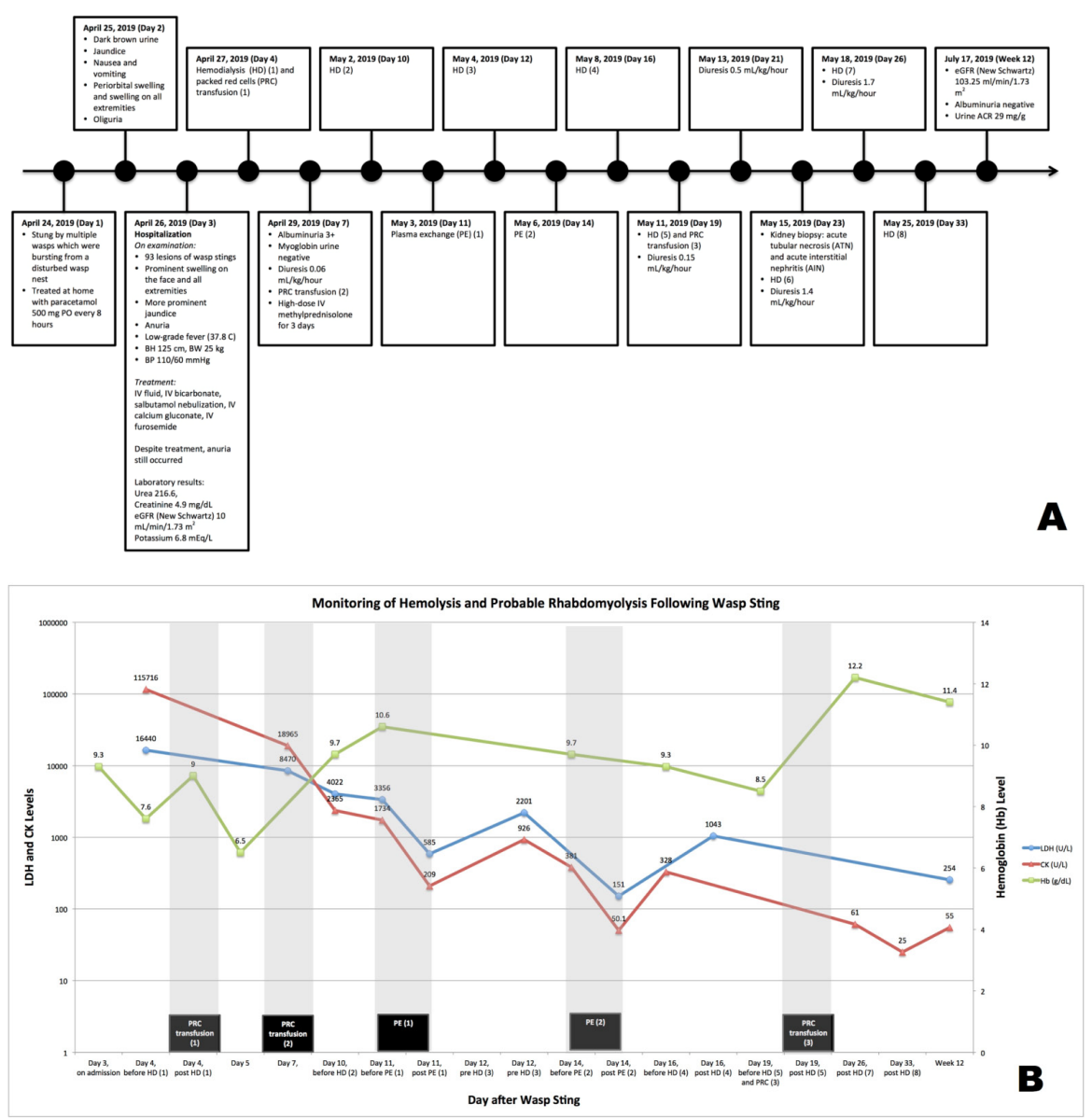

Figure 2. (A) Timeline of the case. (B) Monitoring of hemolysis and probable rhabdomyolysis following wasp sting.

Toxic effects of wasp venom and the release of inflammatory mediators such as interleukin-6 are believed to cause MODS (7). Therefore, receiving a large number of stings ( $>30$ ) would have an enormous impact on the severity of systemic reactions (6). Kidney failure may occur in patients who receive 20 to 200 stings (8). Patients with $>10$ stings had a higher mortality rate than those with $\leq 10$ stings (7). The patient in our case had 93 stings, which resulted in more severe AKI and MODS compared with the previous wasp sting cases reported from Indonesia (30 and 80 stings) (4). However, because our patient had a shorter interval from the incident to hospitalization compared with previously reported cases (4), she had a better outcome.

Massive wasp envenomation leads to accumulation of pigmented casts from intravascular hemolysis in the kidney tubules, injuring the kidneys (8) and complicating excretion of the venom from the body. In such circumstances, renal replacement therapy, such as IHD, continuous veno-venous hemofiltration $(\mathrm{CVVH})$, or a combination of $\mathrm{CVVH}$ and $\mathrm{PE}$, is required (9). The severity of the systemic reaction determines the choice of the modality of renal replacement therapy. For instance, CVVH was preferred in cases of AKI complicated by MODS, while PE was favored in cases of evident rhabdomyolysis and hemolysis (9). In our patient, rhabdomyolysis may have occurred without urinary myoglobin, as indicated by a creatine kinase level five times the upper limit (10). A 2013 review reported that myoglobinuria had high sensitivity but poor specificity for detection of rhabdomyolysis (10).

PE is effective in cases of hemolysis and rhabdomyolysis. However, medical resources in Indonesia are often limited, that in some cases in our center, recommended medication for treatment is not available (11). Due to these drawbacks, the decision to use PE has to be considered carefully in Indonesia. Monthly cost of HD for one patient per month in our dialysis unit is US\$ 1230 (12), based on the fact that the cost per HD session is approximately US\$ 123. By contrast, cost for PE per session is US\$2800. For that reason, HD was chosen immediately upon admission to our patient. Because there was ongoing severe hemolysis marked by deterioration of hemoglobin levels (Figure $2 \mathrm{~b}$ ) and persistent kidney failure after two sessions of $\mathrm{HD}, \mathrm{PE}$ was then arranged, leading to gradual improvement.

PE eliminates the toxins, immune complexes, and antibodies in addition to replacing coagulation factors and other substances with fresh frozen plasma (13). 


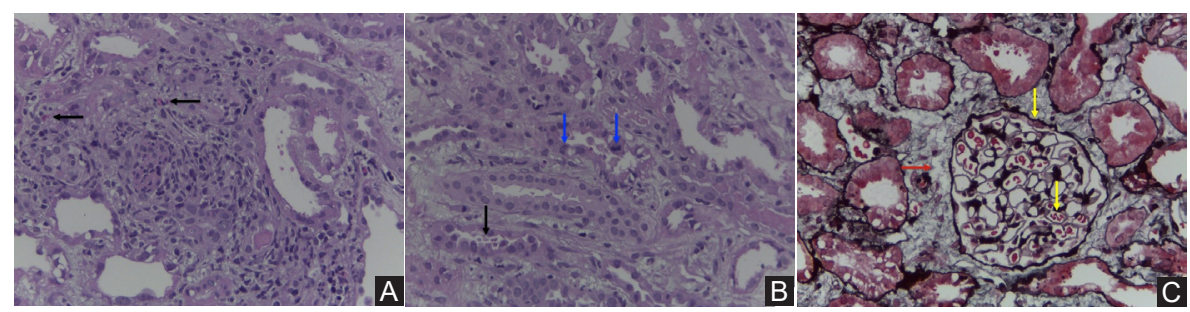

Figure 3. (A) Tubulointerstitial inflammation with eosinophil infiltrate (black arrow), dilated tubules can also be seen (hematoxylin-eosin (HE) $x 40)$. (B) Detachment of epithelial cells to the tubular lumen (black arrow). Epithelial regeneration is noted by the presence of mitotic activity (blue arrow) (HE x40). (C) Normal glomerulus with congested capillaries (yellow arrow) and edematous interstitium (red arrow) (silver trichrome staining x40).

Previous studies have demonstrated that combining PE and $\mathrm{HD}$ for patients requiring rapid removal of toxins is effective, cost-saving, and can shorten the duration of hospitalization $(14,15)$. A study in 2013 showed that 8 out of 36 patients who received only HD after receiving more than 50 wasp stings eventually developed chronic kidney disease, whereas patients who received CVVH or combination of CVVH and PE were recovered completely (9). Hemodialysis caused more intradialytic hypotension and may have induced kidney ischemia, leading to chronic kidney disease (9). Furthermore, CVVH and/or $\mathrm{PE}$ were suggested to produce more effective clearance of large molecular toxins, such as phospholipases and hyaluronidases; which are two important components in wasp venom causing hemolysis $(8,9)$. Additionally, PE is believed to be more effective in removing myoglobulin and creatine kinase which are involved in rhabdomyolysis.

As treatment modalities advance, the outcome of AKI as well as MODS secondary to wasp sting should be impeccable. The outcome of the present case was satisfactory based on complete recovery of kidney function to normal within 12 weeks, as indicated by normal estimated glomerular filtration rate (eGFR) and negative albuminuria. In previously published wasp sting cases, 6 months (1) and 10 months (5) were reported as the time required to completely normalize the kidney function.

\section{Conclusion}

In conclusion, this case showed that immediate admission to the hospital following multiple wasp stings (particularly $>10$ stings) to initiate early dialysis is important to promptly remove toxins and thus will preserve kidney function. Additionally, high-dose methylprednisolone as initial treatment was found to be beneficial in acute interstitial nephritis. This case also showed that PE can be beneficial in cases of hemolysis and rhabdomyolysis complicated by MODS. The outcome of multiple wasp stings should not be devastating, because healthcare services are now more advanced.

\section{Acknowledgments}

We would like to express our gratitude to Professor Taralan Tambunan, Professor Partini Pudjiastuti Trihono, and Sudung Oloan Pardede, $\mathrm{MD}, \mathrm{PhD}$ for their care of the patients in the Department of Child Health, Faculty of Medicine, Universitas Indonesia-Cipto Mangunkusumo Hospital; and ENAGO (http://www.enago.com) for the careful reading and editing of this manuscript.

\section{Authors' contribution}

AG and CGA performed the literature search, data collection, analysis, and interpretation. ELH, AG, and CGA wrote the first draft of the manuscript. MR, HAP, and MS performed data collection and analysis and critically reviewed the manuscript. All authors read and approved the final version of the manuscript.

\section{Conflicts of interest}

The authors have no conflicts of interest to report.

\section{Ethical considerations}

Written informed consent for the publication of this case report and accompanying images was obtained from the patient's parents. Ethical issues, such as plagiarism, misconduct, falsification, double publication, and redundancy, have been completely reviewed by the authors.

\section{Funding/Support}

This case report did not receive any specific grant from funding agencies in the public, commercial, or not-forprofit sectors.

\section{References}

1. Ittyachen AM, Abdulla S, Anwarsha RF, Kumar BS. Multiorgan dysfunction secondary to severe wasp envenomation. Int J Emerg. 2015;8:6. doi: 10.1186/s12245-015-0054-7.

2. Bilo MB, Bonifazi F. The natural history and epidemiology of insect venom allergy: clinical implications. Clin Exp Allergy. 2009;39:1467-1476. doi: 10.1111/j.13652222.2009.03324.x.

3. Murhayati T. Fakta Dibalik Sengatan Tawon Vespa. 2019. https://dinkesjatengprov.go.id/v2018/2019/11/28/faktadibalik-sengatan-tawon-vespa/. Accessed December 27, 2019.

4. Ambarsari CG, Sindih RM, Saraswati M, Trihono PP. Delayed admission and management of pediatric acute kidney injury and multiple organ dysfunction syndrome in 
children with multiple wasp stings: a case series. Case Rep Nephrol Dial. 2019;9:137-148. doi: 10.1159/000504043.

5. Yang SH, Song YH, Kim TH, Kim SB, Han SY, Kim HS, et al. Acute pancreatitis and rhabdomyolysis with acute kidney injury following multiple wasp stings. Case Rep Nephrol. 2017;2017:8596981. doi: 10.1155/2017/8596981.

6. Han-Min W, Feng L, Mei-Lan Z, Rong L, Hong-Bao L, Chen $\mathrm{H}$, et al. Successful treatment of multiple organ failure after wasp stings in an elderly patient. Int J Gerontol. 2012;6:5253. doi: 10.1016/j.ijge.2012.01.002.

7. Xie C, Xu S, Ding F, Xie M, Lv J, Yao J, et al. Clinical features of severe wasp sting patients with dominantly toxic reaction: analysis of 1091 cases. PLoS One. 2013;8:e83164. doi: 10.1371 /journal.pone.0083164.

8. Dongol Y, Shrestha RK, Aryal G, Lakkappa DB. Hymenoptera stings and the acute kidney injury. EMJ Nephrol. 2013;1:68-75.

9. Zhang L, Yang Y, Tang Y, Zhao Y, Cao Y, Su B, et al. Recovery from AKI Following Multiple Wasp Stings: A Case Series. Clin J Am Soc Nephrol. 2013;8:1850-1856. doi: 10.2215/ CJN.12081112.

10. Keltz E, Khan FY, Mann G. Rhabdomyolysis. The role of diagnostic and prognostic factors. Muscles Ligaments
Tendons J. 2013;3:303. doi: 10.11138/mltj/2013.3.4.303.

11. Ambarsari CG, Bermanshah EK, Putra MA, Pardede SO. Effective management of peritoneal dialysis-associated hydrothorax in a child: a case report. Case Rep Nephrol Dial. 2020;10:18-25. doi: 10.1159/000506119.

12. Ambarsari CG, Trihono PP, Kadaristiana A, Tambunan T, Mushahar L, Puspitasari HA, et al. Five-year experience of continuous ambulatory peritoneal dialysis in children: a single center experience in a developing country. Med J Indones. 2019;28:329-37. doi: 10.13181/mji.v28i4.3807.

13. Yuan H, Chen S, Hu F, Zhang Q. Efficacy of two combinations of blood purification techniques for the treatment of multiple organ failure induced by wasp stings. Blood Purif. 2016;42:49-55. doi: 10.1159/000442740.

14. Schaefer B, Ujszaszi A, Schaefer S, Heckert KH, Schaefer F, Schmitt CP. Safety and efficacy of tandem hemodialysis and plasma exchange in children. Clin J Am Soc Nephrol. 2014;9:1563-1570. doi: 10.2215/CJN.12581213.

15. Pérez-Sáez MJ, Toledo K, Ojeda R, Crespo R, Soriano S, Álvarez de Lara MA, et al. Tandem plasmapheresis and hemodialysis: efficacy and safety. Ren Fail. 2011;33:765769. doi: $10.3109 / 0886022 X .2011 .599912$.

Copyright $\odot 2020$ The Author(s); Published by Nickan Research Institute. This is an open-access article distributed under the terms of the Creative Commons Attribution License (http://creativecommons.org/licenses/by/4.0), which permits unrestricted use, distribution, and reproduction in any medium, provided the original work is properly cited. 